\title{
A Hermetic Seal Using Composite Thin-Film In/Sn Solder as an Intermediate Layer and Its Interdiffusion Reaction with $\mathrm{Cu}$
}

\author{
LI-LING YAN, ${ }^{1,3}$ CHENG-KUO LEE,,${ }^{1,2,4}$ DA-QUAN YU, ${ }^{1}$ AI-BIN YU, ${ }^{1}$ \\ WON-KYOUNG CHOI, ${ }^{1}$ JOHN-H LAU, ${ }^{1}$ and SEUNG-UK YOON ${ }^{1}$
}

1.-Institute of Microelectronics, Agency for Science \& Technology and Research (A*STAR), 11 Science Park II, Singapore 117685, Singapore. 2.-Department of Electrical and Computer Engineering National University of Singapore, 4 Engineering Drive 3, Singapore 117576, Singapore. 3.—e-mail: yanll@ime.a-star.edu.sg. 4.—e-mail: elelc@nus.edu.sg

\begin{abstract}
A bonding joint between $\mathrm{Cu}$ metallization and evaporated $\mathrm{In} / \mathrm{Sn}$ composite solder is produced at a temperature lower than $200^{\circ} \mathrm{C}$ in air. The effects of bonding temperature and duration on the interfacial bonding strength are studied herein. Cross sections of bonding joints processed at different bonding conditions were examined by scanning electron microscopy (SEM). The optimal condition, i.e., bonding temperature of $180^{\circ} \mathrm{C}$ for $20 \mathrm{~min}$, was chosen because it gave rise to the highest average bonding strength of $6.5 \mathrm{MPa}$, and a uniform bonding interface with minimum voids or cracks. Good bond formation was also evidenced by scanning acoustic imaging. For bonding couples of patterned dies, a helium leak rate of $5.8 \times 10^{-9} \mathrm{~atm} \mathrm{cc} / \mathrm{s}$ was measured, indicating a hermetic seal. The interfacial reaction between $\mathrm{Cu}$ and $\mathrm{In} / \mathrm{Sn}$ was also studied. Intermetallic compounds (IMCs) such as AuIn, $\mathrm{Cu}_{6} \mathrm{Sn}_{5}$, and $\mathrm{Cu}_{11} \mathrm{In}_{9}$ were detected by means of x-ray diffraction analysis (XRD), and transmission electron microscopy (TEM) accompanied by energy-dispersive x-ray (EDX) spectroscopy. Chemical composition analysis also revealed that solder interlayers, Sn, and In were completely converted into IMCs by reaction with $\mathrm{Cu}$. All the IMCs formed in the joints have remelting temperatures above $300^{\circ} \mathrm{C}$ according to the $\mathrm{Cu}-\mathrm{In}, \mathrm{Cu}-\mathrm{Sn}$, and $\mathrm{Au}-\mathrm{In}$ phase diagrams. Therefore, the joint is able to sustain high service temperatures due to the presence of these IMCs.
\end{abstract}

Key words: In/Sn solder, low-temperature bonding, interfacial reaction, intermetallic compounds, copper

\section{INTRODUCTION}

Hermetic seals are required for many micro-electromechanical system (MEMS) and optoelectronics devices, which must be impervious to external influences such as moisture and air. Conventional hermetic wafer bonding technologies such as fusion bonding, anodic bonding, Au-Sn eutectic soldering, $\mathrm{Cu}-\mathrm{Cu}$ bonding, and frit glass bonding can only be conducted at processing temperatures above $250^{\circ} \mathrm{C}^{1}$ However, a low-temperature bonding process is desirable for a hermetic seal to reduce the

(Received April 6, 2008; accepted September 2, 2008;

published online October 16, 2008) thermally induced warpage in these devices. An In-Sn-based alloy is a very attractive lead-free solder material for a bonding joint due to its low melting temperature $\left(<232^{\circ} \mathrm{C}\right)$. Especially the eutectic In-48wt.\% Sn alloy has received considerable attention due to its low melting point of $118^{\circ} \mathrm{C} .{ }^{2-7}$

There are many methods to apply the solder alloy as a bonding interlayer, e.g., solder paste printing, ${ }^{2}$ molten solder dipping, ${ }^{3}$ and electroplating. ${ }^{4}$ One such method is physical vapor deposition (PVD) technology, which forms thin films of In or/and Sn on substrates such as $\mathrm{Cu}$ or $\mathrm{Au}$. Under certain bonding conditions, the solder materials interact with $\mathrm{Cu}$ or $\mathrm{Au}$ to form a bonding joint. ${ }^{5-8}$ This process often involves so-called diffusion soldering, ${ }^{9}$ a 
joining method that combines features of conventional soldering and diffusion bonding processes. The bonding is produced when the substrate metal dissolves into the molten solder and rapidly reacts to form intermetallic compounds (IMCs) with the solder materials. When the molten solder layer is sandwiched between layers of substrate metals, the whole layer of molten solder may be consumed through the formation of high-melting IMCs. ${ }^{9}$ Thus, the obtained bonding joint can survive subsequent manufacturing operations that may involve higher temperatures.

Thin-film solder In and/or Sn as an intermediate bonding layer has recently been used in lowtemperature wafer bonding for microelectronic packaging. ${ }^{5-8}$ Hermetic packaging has also been developed at temperatures as low as $150^{\circ} \mathrm{C}$ by using an In-Sn alloy. ${ }^{8}$ However, no-one has studied the interfacial reaction of thin-film solder with the substrate and the remelting temperature of the final joint, which are very important in manufacturing operations such as multiple reflows. With a highmelting seal, not only can the sealed packages be engaged in subsequent soldering steps, but also joint creep resistance and dimensional stability can be improved. Many studies have been carried out on the characterization of the interfacial reaction between a $\mathrm{Cu}$ substrate and bulk In-Sn alloy, $3,10-15$ where the eutectic solder In-48wt.\% Sn is applied on the substrate either by dipping into a molten solder bath $^{3,10-12}$ or sandwiching a solder foil. ${ }^{10-12}$ However, the reaction between $\mathrm{Cu}$ and bulk solder should be different from the thin-film case because in the latter case there is only a limited amount of solder material in contact with the substrate and the chemical composition in the solder layers is inhomogeneous. ${ }^{16}$

In this work, low-temperature bonding based on $\mathrm{Sn} / \mathrm{In}$ composite solder has been developed. Bonding quality is evaluated by means of pull testing, crosssection observation, acoustic imaging, and helium leak rate testing. The interfacial reaction between $\mathrm{Cu}$ and the composite solder was studied by means of scanning electron microscopy (SEM), transmission electron microscopy (TEM) with energy-dispersive $\mathrm{x}$-ray (EDX), and x-ray diffraction analysis (XRD).

\section{EXPERIMENTAL PROCEDURE}

Very thin layers of $\mathrm{SiO}_{2} / \mathrm{Si}_{3} \mathrm{~N}_{4} / \mathrm{Ti} / \mathrm{Cu}$ were evaporated sequentially on flat silicon wafers to enhance the adhesion of subsequent layers and also to serve as a seed layer for the subsequent copper electroplating. Their thicknesses were $300 \AA, 1500 \AA$, $500 \AA$, and $1000 \AA$, respectively. Then, a 3- $\mu \mathrm{m}$ copper layer was electroplated on the top of the wafer. As the final step, a $1.6-\mu \mathrm{m}$ indium layer followed by a 1.4- $\mu \mathrm{m}$ tin layer and $50 \mathrm{~nm}$ of Au were deposited on $\mathrm{Cu}$ sequentially by evaporation. The thin layer of $\mathrm{Au}$ was deposited on the Sn layer to inhibit oxygen penetration, which can occur when the samples are removed from the evaporator vacuum chamber and exposed to air. ${ }^{3,4}$ This type of wafer is called base wafer 1; they are mainly used for all the described tests except helium leak rate testing. For the purpose of helium leak rate testing, another type of wafer patterned with a bonding ring and cavity was prepared. The bonding ring had a width of $300 \mu \mathrm{m}$ and a size of $8 \mathrm{~mm} \times 8 \mathrm{~mm}$, while the cavity had a size of $6 \mathrm{~mm} \times 6 \mathrm{~mm}$ with a depth of $250 \mu \mathrm{m}$. This type of patterned wafer is called base wafer 2 . On the bonding ring area, the multilayer materials were deposited in the same sequence and with the same thickness as on base wafer 1 .

To perform the bonding, cap silicon wafers were prepared in the same way as the base wafers except without the $\mathrm{In} / \mathrm{Sn} / \mathrm{Au}$ layer on the electroplated $\mathrm{Cu}$ surface. Similarly, cap wafer 1 was a flat silicon wafer, and cap wafer 2 was a ring patterned wafer. The bonding pair with the multilayer structure is shown schematically in Fig. 1.

Both cap and base wafers were then diced into small, $10 \mathrm{~mm} \times 10 \mathrm{~mm}$ dies. Before bonding, cap dies were first cleaned with acetic acid to remove the copper oxide layer. Then the bonding couples, i.e., cap dies with their corresponding base dies, were thermocompressed in air by using a flip-chip bonder (a)
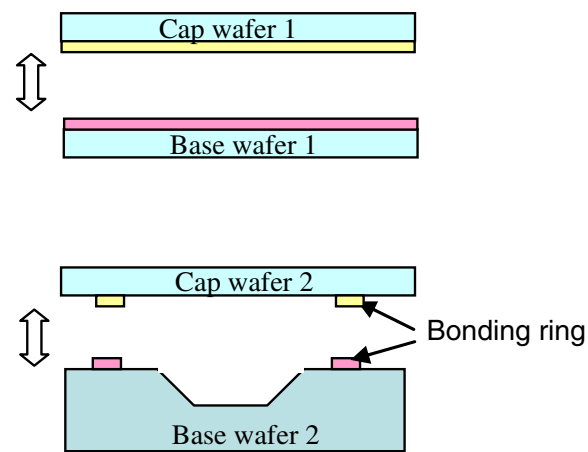

(b)

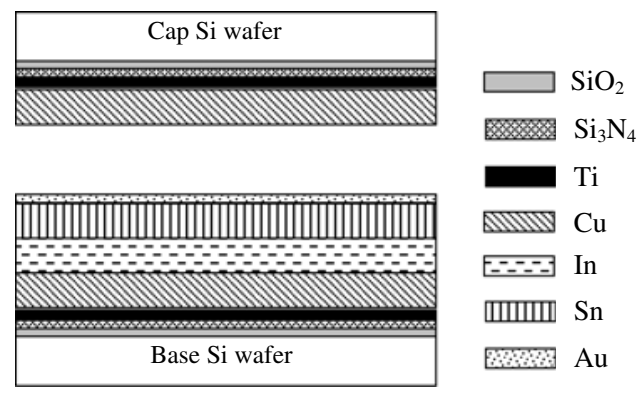

Fig. 1. (a) Schematic of bonding pairs for the flat wafer and patterned wafer. (b) Multilayer material structure on cap wafer and base wafer. 
(SUSS FC 150). For dies from cap wafer 1 and base wafer 1, i.e., flat dies, bonding was carried out under various conditions. The applied bonding pressure for all the samples in this work was $1.5 \mathrm{MPa}$, and the bonding temperature ranged from $140^{\circ} \mathrm{C}$ to $180^{\circ} \mathrm{C}$, and the duration from $5 \mathrm{~min}$ to $20 \mathrm{~min}$. The optimal condition which gave the best joint was used for the bonding of patterned dies. Rosin mildly activated flux (FLUXOT-84032, Indium Co., Utica, NY) was applied on the surface of base dies before bonding in order to facilitate soldering.

Bonding couples were characterized by pull testing to evaluate the interfacial bonding strength. They were glued with a customized fixture and mounted on an Instron tensile machine. The pull test was preformed at a crosshead speed of $0.01 \mathrm{~mm} / \mathrm{s}$. The strength value was averaged over five samples tested. The fractured surfaces after the pull tests were studied by SEM/EDX and XRD using $\mathrm{Cu} K \alpha$ radiation. Cross sections for SEM study were prepared by grinding the specimens with $\mathrm{SiC}$ paper, and polished with $1.0-\mu \mathrm{m}$ and $0.3-\mu \mathrm{m}$ alumina powders. TEM/EDX examination was also performed on the joint cross section. The thin foil preparation for TEM was carried out following the procedure indicated in Ref. 17. Acoustic imaging by scanning acoustic microscopy (SAM) was used for nondestructive study of the bond interface. The process involves launching ultrasonic waves into the samples at a frequency of $230 \mathrm{MHz}$ using a piezoelectric transducer. The same transducer also acts as a receiver of the reflected waves from the sample. The hermeticity of the ring seals for the patterned dies was evaluated by helium leak rate testing (MIL-STD-883).

\section{RESULTS AND DISCUSSION}

\section{Effect of Bonding Conditions and Cross-Section Observations}

The morphology of the contacted surfaces is very important for understanding the bonding process. The top surface of as-received base dies and its cross section was examined by SEM, as shown in Fig. 2 .
Both views show that the surface is extremely rough and is featured with a granular structure with a grain size of $2 \mu \mathrm{m}$ to $3 \mu \mathrm{m}$. In order to bond surfaces with such rough features, a molten solder layer and high pressure is necessary to fill the gaps between the surfaces.

Figure 3 shows the pull test results of couples bonded under different conditions. The bonding duration and temperature have significant effects on the bonding strength. Bonding at $140^{\circ} \mathrm{C}$ for $5 \mathrm{~min}$ and $20 \mathrm{~min}$ gave rise to a bonding strength of only $0.78 \mathrm{MPa}$ and $2.93 \mathrm{MPa}$, respectively. Increasing the temperature to $160^{\circ} \mathrm{C}$ led to a higher bonding strength of $3.6 \mathrm{MPa}$ and $4.8 \mathrm{MPa}$ for the same two bonding durations, respectively. A further increase of temperature to $180^{\circ} \mathrm{C}$ produced an average bonding strength of $6.5 \mathrm{MPa}$ and $3.2 \mathrm{MPa}$ when bonded for $20 \mathrm{~min}$ and $5 \mathrm{~min}$, respectively. According to the pull test results, the optimal bonding condition, i.e., $180^{\circ} \mathrm{C}$ and $20 \mathrm{~min}$, was selected for the bonding of patterned dies.

At a bonding temperature of $140^{\circ} \mathrm{C}$, which is lower than the melting point of In, i.e., $156^{\circ} \mathrm{C}$, the In layer cannot melt. The contacted surfaces are joined

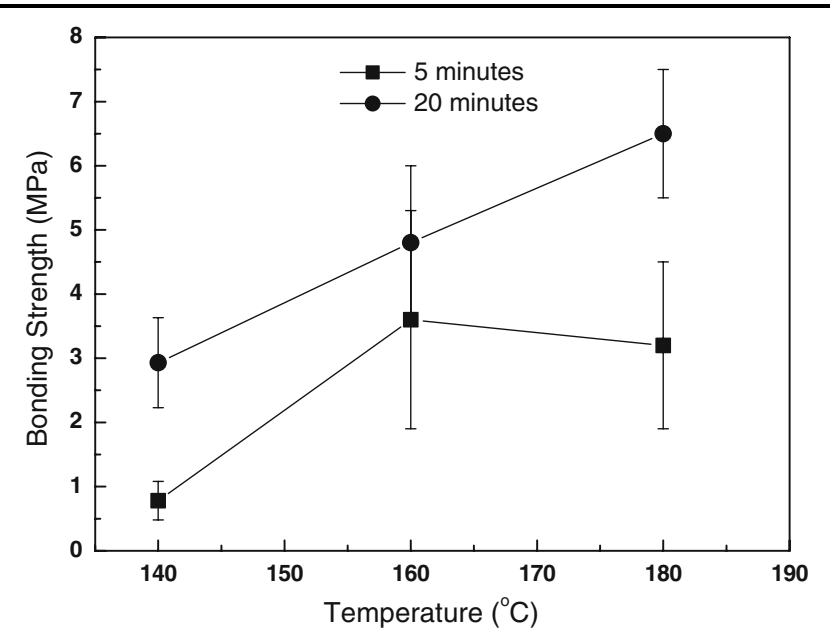

Fig. 3. Effect of bonding conditions with various temperatures and durations on bonding strength.

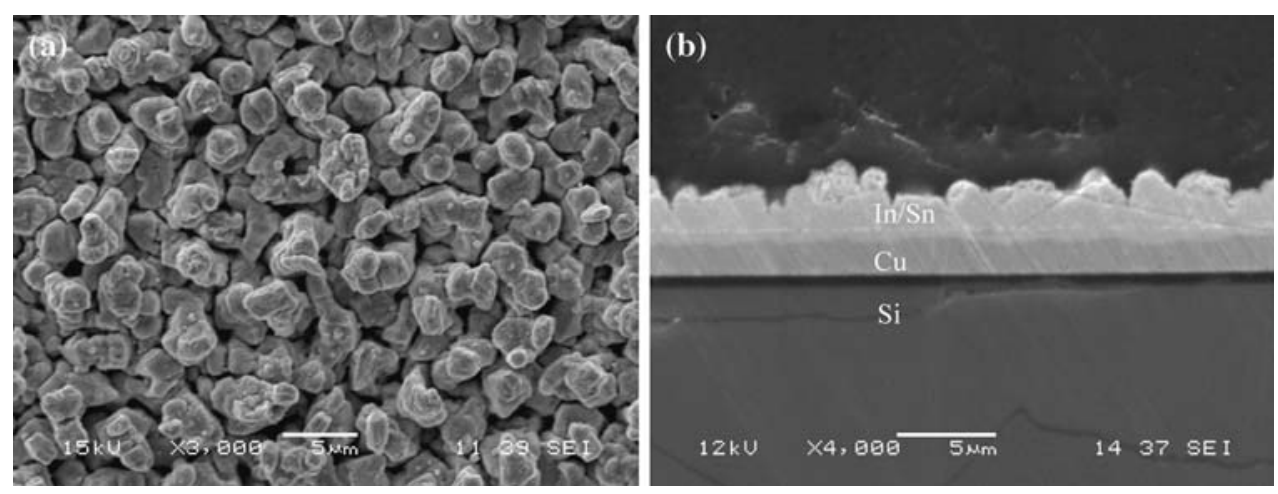

Fig. 2. SEM images of as-received evaporated composite coating surface: (a) top view and (b) cross section. 

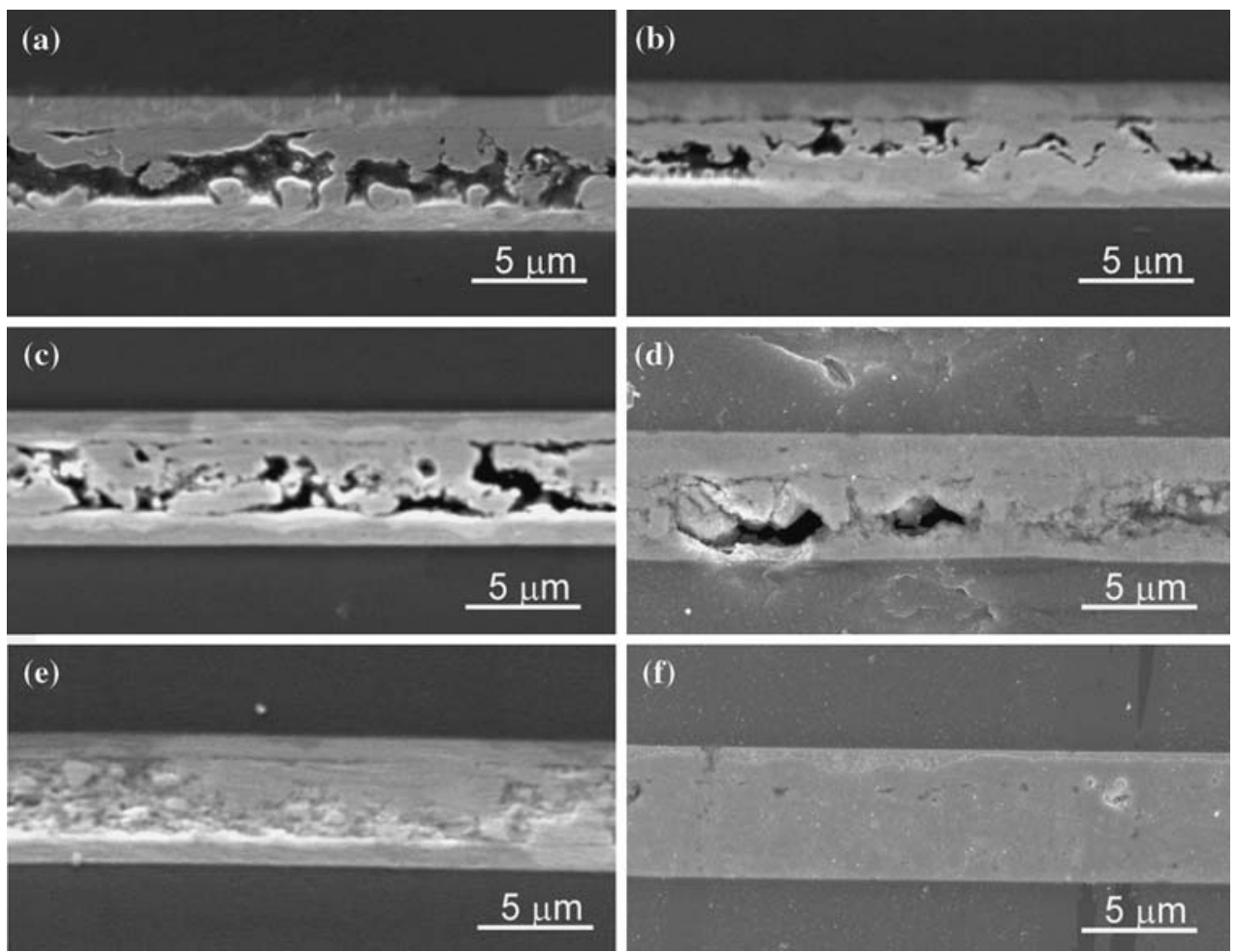

Fig. 4. Cross sections of bonding couples obtained at different bonding conditions (a) $140^{\circ} \mathrm{C}, 5 \mathrm{~min}$; (b) $140^{\circ} \mathrm{C}, 20 \mathrm{~min}$; (c) $160^{\circ} \mathrm{C}, 5 \mathrm{~min}$; (d) $160^{\circ} \mathrm{C}, 20 \mathrm{~min}$; (e) $180^{\circ} \mathrm{C}, 5 \mathrm{~min}$; and (f) $180^{\circ} \mathrm{C}, 20 \mathrm{~min}$.

together only by deformation due to the applied pressure, but the asperities on the rough surfaces cannot be compensated, as is evident from the wide gap present along the interface, as shown in Fig. 4a and $b$. A longer bonding time facilitates greater surface deformation and causes better contact and shows less gaps. As a result, the bonding strength is higher than that bonded for 5 min. A similar observation was made for joints produced at $160^{\circ} \mathrm{C}$, as shown in Fig. 4c and d. The bonding interface still leaves large gaps, although this improved when bonded for a longer time. This is because the temperature of $160^{\circ} \mathrm{C}$ is only slightly higher than the melting point of In, so the solder layer is only partially melted and cannot fill the large gaps.

In contrast, the joints produced at $180^{\circ} \mathrm{C}$ showed much less voids or even a void-free contact, as shown in Fig. 4e and $\mathrm{f}$. The thickness of the joint is uniform throughout the whole contact area with a typical value of $6.2 \pm 0.5 \mu \mathrm{m}$. The bond couples are in good contact and no interface line is observed, which means that the intermediate solder layers melted during the bonding process and leveled off the troughs between grains.

SEM microscopy and EDX composition mapping of the fractured surface after pull testing display a combined cohesive and adhesive failure mode, as shown in Fig. 5. The surface shown is that of a cap die separated from its bond couple at a bonding strength of 7.3 $\mathrm{MPa}$, which is a relatively high value among the tested samples. The flat regions seen in
Fig. 5a represent adhesive failure of the $\mathrm{Cu} / \mathrm{IMC}$ interface where the element mapping reveals $\mathrm{Cu}$ as the dominant element, whereas the other regions represent cohesive failure within IMCs, as the elements $\mathrm{Cu}, \mathrm{In}$, and $\mathrm{Sn}$ are evenly distributed without clustering. This mixed failure mode suggests that the adhesion of the solder layer and $\mathrm{Cu}$ is very good due to their interfacial reaction.

\section{Sealing Quality Assessment}

SAM is a popular tool for monitoring bonding interfaces. During acoustic imaging the reflection intensity of the ultrasound waves is captured through the bond interface. Ultrasound waves are reflected when they encounter a material discontinuity, such as voids, and are displayed with white pixels in images. Otherwise they have low reflection when they pass through areas of material continuum, which indicates good bond formation, signified by dark pixels in the images. The acoustic images of the bond interface for flat dies and patterned dies bonded at $180^{\circ} \mathrm{C}$ for $20 \mathrm{~min}$ are shown in Fig. 6a and $\mathrm{b}$, respectively. A uniform bond with minimum void formation is observed. Especially for the patterned dies, the whole bonding ring is a uniform gray color, indicating that the bonded couple has intimate contact, and that no voids or delamination occurred. The helium leak rate test showed that the bonding couples of the patterned dies were hermetic seals with an average leak rate value of 

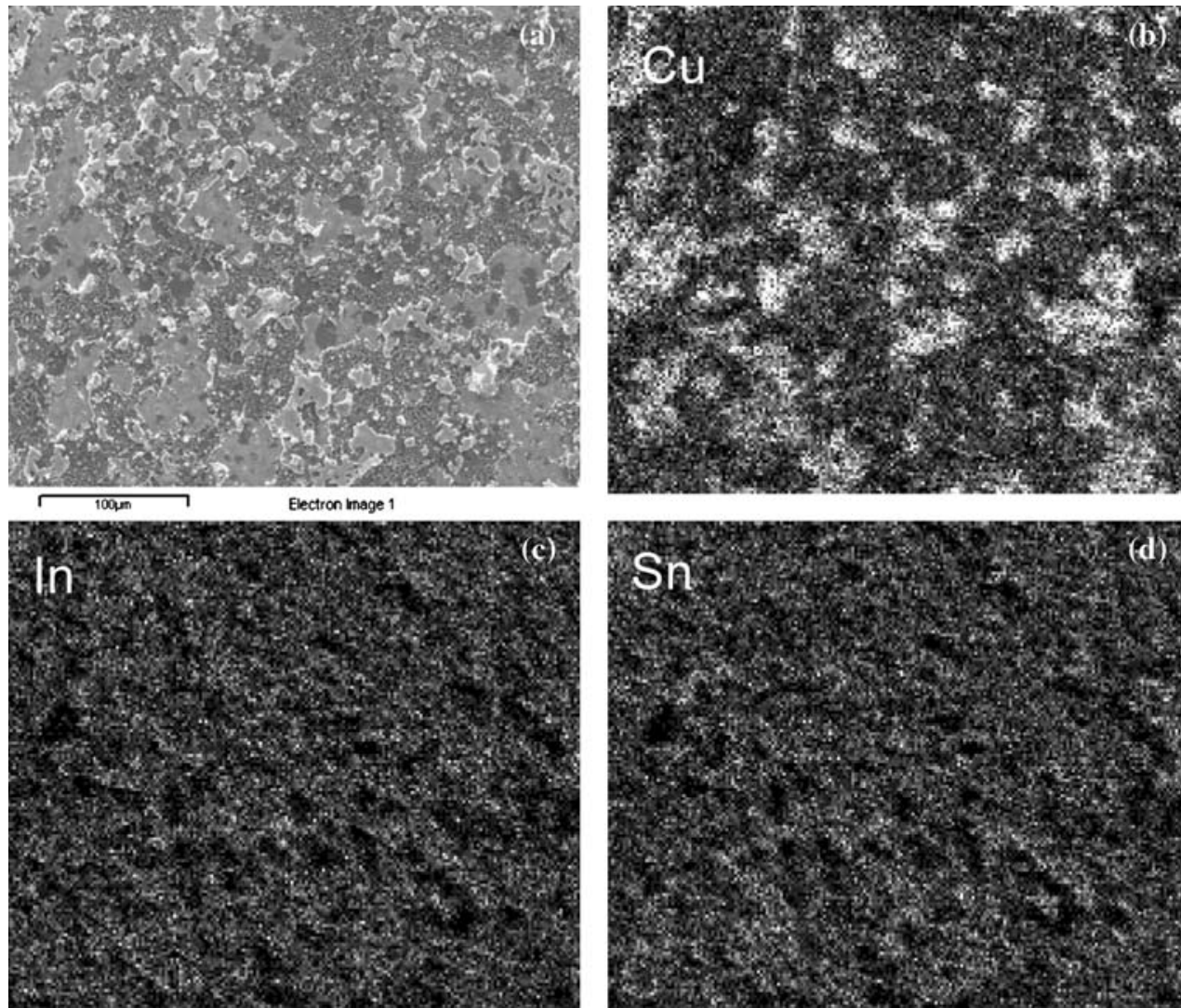

Fig. 5. Fracture surface examination after pull testing. (a) SEM photography and EDX element mapping: (b) Cu, (c) In, and (d) Sn.
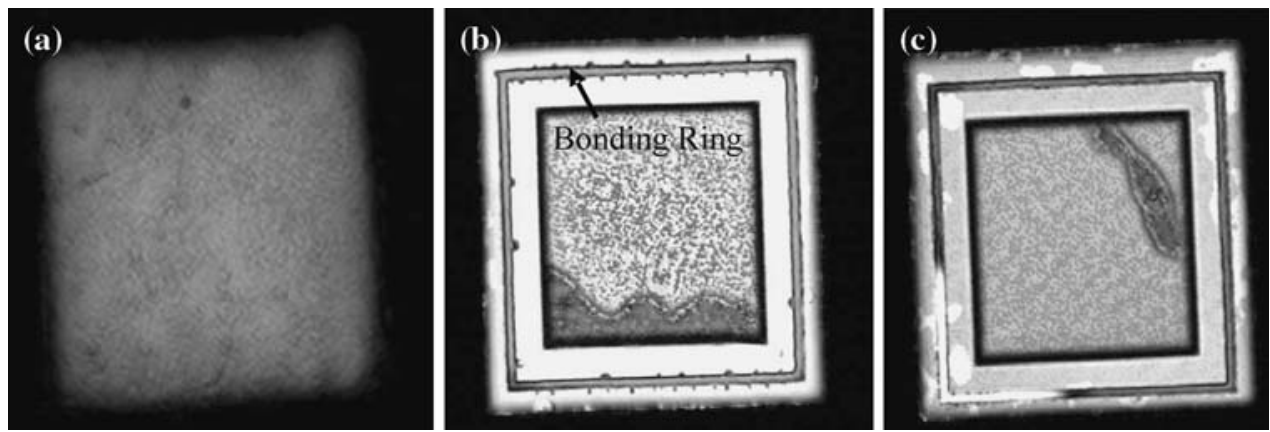

Fig. 6. Acoustic images of (a) a well-bonded flat silicon dice, (b) a well-bonded patterned dice at $180^{\circ} \mathrm{C}$ for 20 min, and (c) a poorly bond interface formed at $140^{\circ} \mathrm{C}$ for $20 \mathrm{~min}$.

$5.8 \times 10^{-9} \mathrm{~atm} \mathrm{cc/s}$ (five tested samples). For comparison, a poor bond interface formed at $140^{\circ} \mathrm{C}$ for $20 \mathrm{~min}$, exhibiting voids or delamination as white pixels, is shown in Fig. 6c. These poorly bonded samples were either separate on helium leak rate test or exhibited a leak rate on the order of $10^{-8} \mathrm{~atm} \mathrm{cc/s}$.

\section{$\mathbf{C u} / \mathbf{I n} / \mathbf{S n} / \mathbf{C u}$ Interfacial Reaction}

For the interfacial reaction study, all the studied samples were bonded at a temperature of $180^{\circ} \mathrm{C}$ for $20 \mathrm{~min}$. The fractured surfaces after the pull test were studied by XRD to examine the IMCs that had evolved in the bonding reaction zone. $\mathrm{AuIn}_{2}$, $\mathrm{Cu}_{6} \mathrm{Sn}_{5}$, and $\mathrm{Cu}_{11} \mathrm{In}_{9}$ phases were found on XRD analysis, as shown in Fig. 7. No Sn or In peak was detected.

Since the IMC layers are relatively thin, the TEM technique was chosen as it provides local chemical analysis. Figure 8 shows TEM images of the region close to the base material silicon and interfacial reaction region between $\mathrm{Cu}$ and solder intermediate layers. It is seen from Fig. 8a that, on the top of the silicon, the first layer is silicon oxide, followed by silicon nitride, titanium, and copper. The interfaces between each layer are void free and uniform. The silicon oxide and nitride layers provide good 

and Its Interdiffusion Reaction with $\mathrm{Cu}$

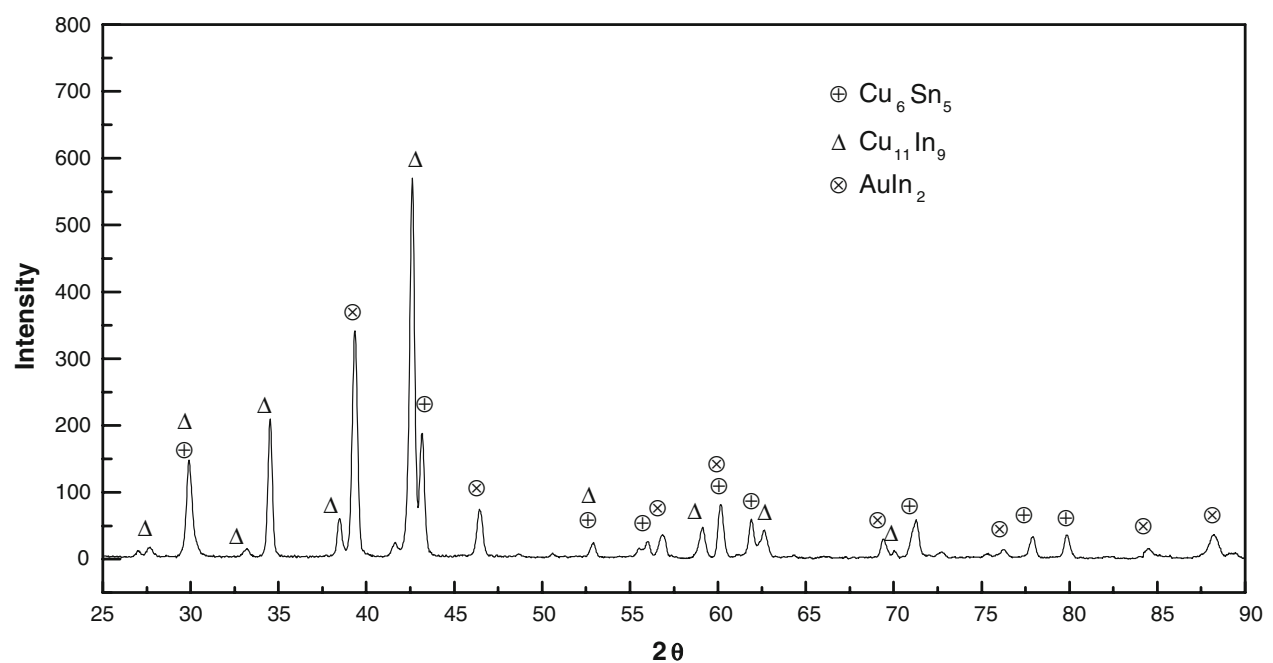

Fig. 7. XRD results of the fracture surface after pull testing of samples bonded at $180^{\circ} \mathrm{C}$ for $20 \mathrm{~min}$.
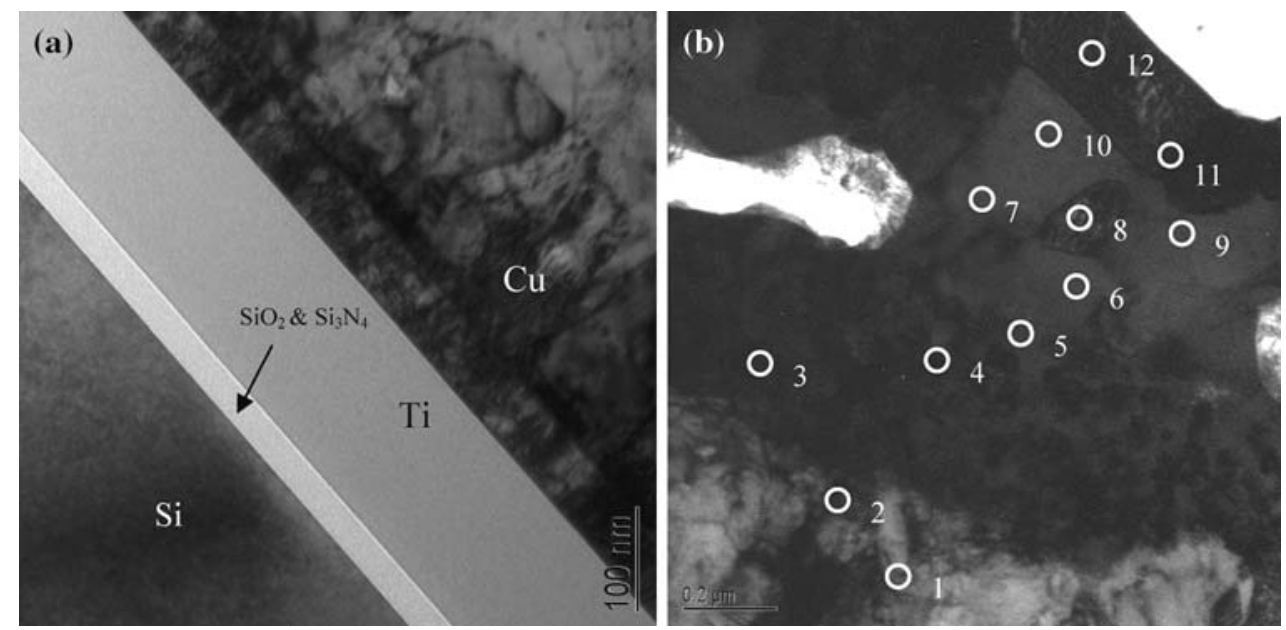

Fig. 8. TEM images showing the bonding interface (a) in the silicon region and (b) at the interface region.

adhesion layers between the subsequent metal layer and silicon base.

Figure $8 \mathrm{~b}$ shows the reaction zone between $\mathrm{Cu}$ and the In/Sn solder interlayer. Small grains are clearly visible in the reaction zone. The elemental composition results of the selected points are summarized in Table I. Two IMCs can be identified along the main reaction zone, i.e., $\mathrm{Cu}_{6}(\mathrm{Sn}, \mathrm{In})_{5}$ and $\mathrm{Cu}_{11}(\mathrm{In}, \mathrm{Sn})_{9}$. This result is consistent with the XRD results, which confirmed the presence of these two IMCs in the bonding interface. The composition of $\mathrm{Cu}$ reduced gradually from 56 at.\% to 48 at.\% from the near- $\mathrm{Cu}$ to the near-In region. EDX analysis suggested that unreacted $\mathrm{Cu}$ remained that was not used for joint formation. At the edge of the bonding interface the $\mathrm{Cu}$ composition drops dramatically and only In and Au dominate with the composition shown as points 11 and 12 in Table I, i.e., $\mathrm{Cu}_{5.9} \mathrm{Au}_{34.0} \mathrm{In}_{59.0} \mathrm{Sn}_{1.1}$ and $\mathrm{Cu}_{5.1} \mathrm{Au}_{33} \mathrm{In}_{60.2} \mathrm{Sn}_{1.7}$,
Table I. Summary of Point EDX Analysis Along the Interface Shown in the TEM Image

\begin{tabular}{|c|c|c|c|c|c|}
\hline \multirow[b]{2}{*}{ Point } & \multicolumn{4}{|c|}{ Composition (at.\%) } & \multirow{2}{*}{$\begin{array}{c}\text { Equilibrium } \\
\text { Phase }\end{array}$} \\
\hline & $\mathbf{C u}$ & In & Sn & $\mathbf{A u}$ & \\
\hline 1 & 99.5 & 0.3 & 0.2 & 0 & $\mathrm{Cu}$ \\
\hline 2 & 99.0 & 0.3 & 0.2 & 0.5 & $\mathrm{Cu}$ \\
\hline 3 & 56.0 & 28.5 & 15.5 & 0 & $\mathrm{Cu}_{11}(\mathrm{In}, \mathrm{Sn})_{9}$ \\
\hline 4 & 54.6 & 31.3 & 13.7 & 0.4 & $\mathrm{Cu}_{11}(\mathrm{In}, \mathrm{Sn})_{9}$ \\
\hline 5 & 52.1 & 30.4 & 17.0 & 0.5 & $\mathrm{Cu}_{11}(\mathrm{In}, \mathrm{Sn})_{9}$ \\
\hline 6 & 51.4 & 28.3 & 19.6 & 0.7 & $\mathrm{Cu}_{11}(\mathrm{In}, \mathrm{Sn})_{9}$ \\
\hline 7 & 50.2 & 31.2 & 18.3 & 0.3 & $\mathrm{Cu}_{11}(\mathrm{In}, \mathrm{Sn})_{9}$ \\
\hline 8 & 48.1 & 21.0 & 30.4 & 0.5 & $\eta-\mathrm{Cu}_{6}(\mathrm{Sn}, \mathrm{In})_{5}$ \\
\hline 9 & 49.8 & 23.4 & 26.6 & 0.2 & $\eta-\mathrm{Cu}_{6}(\mathrm{Sn}, \mathrm{In})_{5}$ \\
\hline 10 & 50.3 & 20.7 & 29.0 & 0 & $\eta-\mathrm{Cu}_{6}(\mathrm{Sn}, \mathrm{In})_{5}$ \\
\hline 11 & 5.9 & 59.0 & 1.1 & 34.0 & $\mathrm{Au}(\mathrm{In}, \mathrm{Sn})_{2}$ \\
\hline 12 & 5.1 & 60.2 & 1.7 & 33.0 & $\mathrm{Au}(\mathrm{In}, \mathrm{Sn})_{2}$ \\
\hline
\end{tabular}


which corresponds to an equilibrium phase $\mathrm{AuIn}_{2}$. In the soldering process, while the composite solder layers are in a liquid state, In and Sn compete to react with $\mathrm{Au}$. Although $\mathrm{AuSn}_{4}$ is commonly formed at the interface between $\mathrm{Au}$ and $\mathrm{Sn}$ in some other systems at temperature $<200^{\circ} \mathrm{C},{ }^{18-20}$ the formation of $\mathrm{AuIn}_{2}$ rather than $\mathrm{AuSn}_{4}$ is observed due to the fact that formation of the former IMC has a lower Gibbs free energy compared with Au-Sn compounds. ${ }^{21-23}$ Such favorable formation of $\mathrm{AuIn}_{2}$ is even observed under solid-state diffusion conditions where the Sn layer is between the In and $\mathrm{Au}$ and bonding is conducted at a temperature of $120^{\circ} \mathrm{C}^{24}$

It is interesting to observe that the overall composite solder is molten at the bonding temperature of $180^{\circ} \mathrm{C}$, although the temperature is not high enough to melt Sn, which has a melting temperature of $232^{\circ} \mathrm{C}$. This is because the molten In layer is mixed with the solid-state Sn layer, forming a thin low-melting-temperature In-Sn layer at their interface. From the binary diagram, the eutectic In-Sn alloy has a lower melting point of $118^{\circ} \mathrm{C}$, and at room temperature the Sn content in the $\beta$ phase ranges from 15 wt.\% to 28 wt.\% and the extent of indium in the $\gamma$ phase can reach $\sim 28 \mathrm{wt} . \%$. This means that In and Sn can easily diffuse into each other. Therefore, liquid In and solid Sn could interdiffuse into each other, and as a result the eutectic In-Sn layer grows at the expense of single In and Sn layers until both solder layers have been completely consumed. Notice that the initial overall composition of In and Sn present in the as-received base dies is eutectic, i.e., 48 wt.\% Sn. Although the In also reacts with $\mathrm{Au}$, it only consumes a small portion of the In, which leaves the overall In and Sn compositions slightly shifted to an off-eutectic point, i.e., 50 wt.\% Sn. So, with such a near-eutectic liquid layer, the intrinsic roughness of the evaporated surface can be overcome and thus a good joint interface is observed, as described above. During the soldering process, the subsequent interdiffusion of $\mathrm{Cu}$ and $\mathrm{Sn} / \mathrm{In}$ takes place in the interface region and forms various IMCs. Due to the fully molten status of intermediate layers at the temperature of $180^{\circ} \mathrm{C}$, this may explain why the In atoms can interact with $\mathrm{Au}$ and form $\mathrm{AuIn}_{2}$ in the case that the Sn layer initially lies between the In layer and $\mathrm{Au}$.

The composition analysis and XRD results also suggest that no unreacted In or Sn materials are present after bonding. The solder materials have been completely transformed into IMCs by reaction with copper. This finding implies that bonded joints produced at low temperature can withstand high service temperatures due to the presence of highmelting-point IMCs. From consideration of the phase diagrams, the melting points of $\mathrm{Cu}_{6} \mathrm{Sn}_{5}$, $\mathrm{Cu}_{11} \mathrm{In}_{9}$, and $\mathrm{AuIn}_{2}$ are $430^{\circ} \mathrm{C}, 320^{\circ} \mathrm{C}$, and $580^{\circ} \mathrm{C}$, respectively. Therefore, the thermal stability of the joint is expected to be higher than $300^{\circ} \mathrm{C}$. The measurement of the melting temperature of those IMC-based joints has been reported in another work, which reported no sign of melting below $300^{\circ} \mathrm{C}$ according to differential scanning calorimetry (DSC) analysis. ${ }^{25}$ Such joints with good bond quality and high remelting point produced by the diffusion soldering process are highly desirable in microelectronic packaging such as MEMS and photonic packaging since most of these devices to be packaged are either temperature or stress sensitive.

To further explore low-temperature bonding using thin-film In-Sn solder, several other material configurations in terms of the composite solder layer sequence and layer thickness have been designed based on phase equilibrium calculations. ${ }^{25}$ It is found that, with proper material design and optimal bonding condition, a bonding temperature as low as $120^{\circ} \mathrm{C}$ is feasible without compromising bonding quality.

\section{CONCLUSIONS}

Low-temperature flip-chip bonding using composite thin-film In/Sn solder has been developed in this work. The effects of various bonding conditions in terms of temperature and duration on interfacial bonding strength have been studied. The optimal condition, i.e., bonding temperature of $180^{\circ} \mathrm{C}$ for $20 \mathrm{~min}$, was selected because it led to the highest average bonding strength, i.e., $6.5 \mathrm{MPa}$, and a uniform bonding interface with minimum voids or cracks. For the ring seals of patterned dies, the helium leak rate test showed a leak rate of $5.8 \times$ $10^{-9} \mathrm{~atm} \mathrm{cc} / \mathrm{s}$, which indicates a hermetic seal. The good bond formation at $180^{\circ} \mathrm{C}$ was realized by diffusion soldering, in which $\mathrm{Cu}$ dissolved into solder materials and forms IMCs. Also, their interfacial reaction results in the formation of $\mathrm{Cu}_{6}(\mathrm{Sn}, \mathrm{In})_{5}$ and $\mathrm{Cu}_{11}(\mathrm{In}, \mathrm{Sn})_{9} \mathrm{IMCs}$. AuIn $\mathrm{In}_{2}$ was formed at the very top layer of the interface. No unreacted solder materials were detected in the interface after bonding. All IMCs formed in the joints have a remelting temperature above $300^{\circ} \mathrm{C}$ according to the $\mathrm{Cu}-\mathrm{In}, \mathrm{Cu}-\mathrm{Sn}$, and $\mathrm{Au}-\mathrm{In}$ phase diagrams. Therefore, the joint can sustain high service temperatures as it is formed completely from these IMCs.

\section{ACKNOWLEDGEMENTS}

Chengkuo Lee, PI of IME core Project No. 06-420004, and other authors would like to thank the Agency for Science, Technology, and Research (A*STAR), Singapore, for supporting this research. The authors would also like to thank Sandy Wang, Hnin Wai Yin from Micro-system, Modules, and Components (MMC) Lab for their support of this work, and Jasmine Woo and Dr. Yu Anyan for their assistance in TEM work.

\section{REFERENCES}

1. N. Miki, Sens. Lett. 3, 263 (2005). doi:10.1166/sl.2005.039.

2. S. Sommadossi, W. Gust, and E.J. Mittemeijer, Mater. Chem. Phys. 77, 924 (2002). doi:10.1016/S0254-0584(02)00 192-X.

3. P.T. Vianco, P.F. Hlava, and A.C. Kilgo, J. Electron. Mater. 23, 583 (1994). doi:10.1007/BF02653343. 
4. S.W. Chen, S.K. Lin, and C.F. Yang, J. Electron. Mater. 35, 72 (2006). doi:10.1007/s11664-006-0186-x.

5. T.H. Chuang, H.J. Lin, and C.W. Tsao, J. Electron. Mater. 35, 1566 (2006). doi:10.1007/s11664-006-0150-9.

6. C.C. Lee and S. Choe, Mater. Sci. Eng. A333, 45 (2002).

7. R.W. Chuang and C.C. Lee, Thin Solid Films 414, 175 (2002). doi:10.1016/S0040-6090(02)00424-8.

8. C. Lee, W.F. Huang, and J.S. Shie, Sens. Actuators 85, 330 (2000). doi:10.1016/S0924-4247(00)00338-1.

9. G. Humpston and D.M. Jacobson, Principles of Soldering and Brazing (ASM International: Materials Park, 1993), p. 128.

10. D.R. Frear and P.T. Vianco, Metall. Mater. Trans. A 25, 1509 (1994). doi:10.1007/BF02665483.

11. J.W. Morris Jr., J.L. Free Goldstein, and Z. Mei, JOM 45, 25 (1993).

12. Z. Mei and J.W. Morris Jr., J. Electron. Mater. 21, 401 (1992). doi:10.1007/BF02660403.

13. T.H. Chuang, C.L. Yu, S.Y. Chang, and S.S. Wang J. Electron. Mater. 31, 640 (2002). doi:10.1007/s11664002-0136-1.

14. S. Sommadossi and A.F. Guillermet, Intermetallics 15, 912 (2007). doi:10.1016/j.intermet.2006.10.050.

15. D.G. Kim and S.B. Jung, J. Alloy. Comp. 386, 151 (2005). doi:10.1016/j.jallcom.2004.05.055.
16. K.N. Tu, Mater. Chem. Phys. 46, 217 (1996). doi:10.1016/ S0254-0584(97)80016-8.

17. S. Sommadossi, L. Litynska, P. Zieba, W. Gust, and E.J. Mittemeijier, Mater. Chem. Phys. 81, 566 (2003). doi:10.1016/S0254-0584(03)00076-2.

18. T.K. Lee, S. Zhang, C.C. Wong, A.C. Tan, and D. Hadikusuma, Thin Solid Films 504, 441 (2006). doi:10.1016/j.tsf.2005. 09.112 .

19. L.Y. Hsiao, G.Y. Jang, K.J. Wang, and J.G. Duh, J. Electron. Mater. 36, 1476 (2007). doi:10.1007/s11664-007-0282-6.

20. S.W. Chen and Y.W. Yen, J. Electron. Mater. 30, 1133 (2001). doi:10.1007/s11664-001-0140-x.

21. J.M. Koo and S.B. Jung, J. Electron. Mater. 34, 1565 (2005). doi:10.1007/s11664-005-0166-6.

22. T.H. Chuang, S.Y. Chang, L.C. Tsao, W.P. Weng, and H.M. Wu, J. Electron. Mater. 32, 195 (2003). doi:10.1007/s11664003-0193-0.

23. Y.M. Liu and T.H. Chuang, J. Electron. Mater. 29, 405 (2000). doi:10.1007/s11664-000-0152-y.

24. I. Shohji, S. Fujiwara, S. Kiyono, and F. Kobayashi, Scr. Mater. 40, 815 (1999). doi:10.1016/S1359-6462(99)00007-X.

25. W.K. Choi, D.Q. Yu, C. Lee, L.L. Yan, A.B. Yu, S.U. Yoon, J.H. Lau, G.C. Moon, H.J. Yoon, and M.L. Hyuck, Proceedings of 58th Electronic Components and Technology Conference (Lake Buena Vista, Florida, 2008), p. 1294. 